\title{
Article
}

\section{Cryosphere Services to Support SDGs in High Mountains}

\author{
Jinglin Zhang ${ }^{1,2} \mathbb{D}$, Wei Zhang ${ }^{1, *} \mathbb{(}$, Shiwei Liu ${ }^{1,2}$ and Weiming Kong ${ }^{1,2}$ \\ 1 State Key Laboratory of Cryospheric Science, Northwest Institute of Eco-Environment and Resources, \\ Chinese Academy of Sciences, Lanzhou 730000, China; zhangjinglin@lzb.ac.cn (J.Z.); \\ liushiwei1990@lzb.ac.cn (S.L.); kongwm@lzb.ac.cn (W.K.) \\ 2 College of Resources and Environment, University of Chinese Academy of Sciences, Beijing 100049, China \\ * Correspondence: zhangw06@lzb.ac.cn
}

Citation: Zhang, J.; Zhang, W.; Liu, S.; Kong, W. Cryosphere Services to Support SDGs in High Mountains. Sustainability 2022, 14, 791.

https://doi.org/10.3390/su14020791

Academic Editors: Oz Sahin and Jeroen Meersmans

Received: 18 November 2021

Accepted: 7 January 2022

Published: 11 January 2022

Publisher's Note: MDPI stays neutral with regard to jurisdictional claims in published maps and institutional affiliations.

Copyright: (C) 2022 by the authors. Licensee MDPI, Basel, Switzerland. This article is an open access article distributed under the terms and conditions of the Creative Commons Attribution (CC BY) license (https:// creativecommons.org/licenses/by/ $4.0 /)$.

\begin{abstract}
The cryosphere is able to provide a variety of services for the benefit of human wellbeing and underpins regional sustainable development. The cryosphere deterioration induced by climate change is impacting the services and will subsequently impede the efforts to meet sustainable development goals (SDGs) in high mountain societies. Here, we detail the context of cryosphere services and establish a dataset for its linkage to SDGs. This allows us to uncover its roles in supporting SDGs, directly by a causal connection and indirectly through either cascading effects or interconnection among SDGs. We find that the SDGs in association with the basic needs of high mountain societies are mostly affected by the cryosphere services. The different types of services pitch in with distinctions to be embraced by various SDGs, whilst some play a prominent role in the contribution to a broad range of SDGs. We further investigate how the services behave in their contributions to SDGs, by taking a view via the lens of a network that deciphers the relationship between the services and SDG targets as well as the interconnections among SDG targets. With an insight into the centrality and modularity of services in the network, we then delineate the inherent criticality of services to SDG targets as a whole, and reveal the specificity of services that co-contribute to a cluster of SDG targets in each network community. We take out the services from the network and maintain their interlinks to the targets of each underlying SDG system represented in six key entry points, so that the services critical to the transformation pathways in the entry points for SDGs in high mountains can be identified. Finally, we discuss the trade-offs that can occur in high mountains, which is unique for the cryosphere services. It creates more complexity in the assessment of overall benefits that the cryosphere services may provide to SDGs, and urges the balance that has to be maintained in attaining those services for the transformation.
\end{abstract}

Keywords: cryosphere; cryosphere services; ecosystem services; sustainable development goals; climate change; high mountain regions

\section{Introduction}

The cryosphere is sensitive to climate change with warming occurring at a rate twice the global average [1,2]. It has been demonstrated that climate warming leads to significant changes of the cryosphere in high mountain regions, portrayed by glacier retreat $[3,4]$, snow cover reduction [5], and permafrost degradation [6-8]. The cryosphere plays critical roles, not only in climate systems, but also in supporting societies such as those in mountain regions $[9,10]$. The changes in the cryosphere would harness the impact on meltwater supply paralleled with the declining ability to serve the demand of societies, which would become one of the major challenges faced in high mountains [9,11-13].

The concept of service was initially raised in the ecosystem services framework to establish links between natural resources and socioeconomic development [14,15]. Similarly, the cryosphere offers the services that people may benefit from [16], or the cryosphere services, known as one of the cryosphere contributions that may emerge from the interaction between cryosphere and anthroposphere [17]. The special report of the ocean and 
cryosphere in a changing climate (SROCC) [12] emphasized the impacts of multiscale cryosphere would potentially impact on cryosphere services and consequently on societies, especially the 'Third pole' cryosphere changes and its support to the human environment under climate change [18]. To continuously maintain its services to the societies and ecosystems now and in the future has come down to the issue of sustainable development [12].

The Agenda 2030 of the United Nations (UN) embraces 17 sustainable development goals (SDGs) and 169 corresponding targets to be fulfilled [19]. According to the latest progress report, the situation is grim for achieving the SDGs by the deadline [20]. There are serious challenges in meeting the goals on time. The lack of specific ways to achieve the goals is a crucial reason which hinders the SDG implementation by 2030 [21]. The effective pathway for climate action to meet the SDGs is inherently crucial to drive the transformations towards the 2030 agenda [12,22]. The importance was particularly highlighted in high mountain regions by the International Centre for Integrated Mountain Development (ICIMOD) in 2019 [23]. However, a lack of understanding of how the cryosphere contributes to SDGs hinders the development of effective pathways in high mountains. Reasonable optimization of cryosphere resource allocation requires an understanding of the multiple linkages between SDGs and cryosphere services.

Therefore, in this study, we intend to find the SDGs and corresponding targets that are mostly affected by the cryosphere services, whilst uncovering the services that contribute to a broad range of SDGs overall. By developing a dataset that gives both direct and indirect relations between the services and SDGs as well as associated significance of the relations, we can then dive deep into understanding how the services contribute to SDGs. It is worth bearing in mind that there exists a wide interconnection among SDGs and their targets, as demonstrated by the prevailing synergies and tradeoffs among them [24-27]. A growing literature considers the SDGs as an interlinked network [28]. The network analysis method is efficient in analyzing the interrelationship between multiple targets [29]. We attempt to take into account the effect of interconnection in an overall contribution of cryosphere services to SDGs. The network analysis can effectively coordinate among the complex relationships of the services, which will be able to promote the optimal allocation of cryosphere resources in social-ecology systems and enhance the ability capacity of adaptation to climate changes. In addition, the indicators screened by the centralities of the network are efficient for the subsequent quantitative analysis of the impact of cryosphere services on SDGs.

Meanwhile, considering that there is a lack of clarity about the pathways to meet the targets [27], the Global Sustainable Development Report 2019 [30] proposed six entry points (SEPs) to facilitate the implementation, which includes (1) strengthening human well-being and capabilities, (2) shifting towards sustainable and just economies, (3) building food systems and healthy nutrition patterns, (4) achieving energy decarbonization and universal access to energy, (5) promoting urban and peri-urban development, and (6) securing global environmental commons. Rather than focusing on the specific targets or goals, they emphasize the target clusters in association with basic human needs, economy, agriculture, energy, society, and environment in a more systematic and integrated approach [30]. Here we explore the relationship between the cryosphere services and the six entry points and discuss the themes concerning how to take advantage of the cryosphere services and develop pathways to achieve SDGs in high mountains.

\section{Materials and Methods}

\subsection{Classification of the Cryosphere Services}

The millennium ecosystem services assessment report (MA) [31] framework was applied for the classifications of cryosphere services and development of an evaluation framework $[16,17,32]$. Like the MA framework, cryosphere services are considered to include provisioning, regulating, cultural, and supporting services. Considering the cryosphere in high mountains that generally includes glacier, snow cover, and frozen ground, we categorize all elements in the context of the cryosphere services, as shown in Table 1. 
Table 1. The cryosphere services provided by glacier, snow and frozen ground (including permafrost) in high mountains.

\begin{tabular}{|c|c|c|c|c|c|}
\hline \multicolumn{2}{|c|}{ Cryosphere Services } & Glacier & Snow & Frozen Ground & Explanation and Examples \\
\hline \multirow{3}{*}{$\begin{array}{l}\text { Provisioning } \\
\text { Services }\end{array}$} & Freshwater & $\times$ & $x$ & $x$ & Provision of meltwater \\
\hline & Clean energy & $\times$ & $x$ & $\times$ & $\begin{array}{l}\text { Provision of hydropower and } \\
\text { natural gas hydrate in } \\
\text { frozen ground }\end{array}$ \\
\hline & Snow and ice material & $\times$ & $\times$ & - & $\begin{array}{l}\text { Provision of materials, such as for } \\
\text { construction and decoration }\end{array}$ \\
\hline \multirow{4}{*}{$\begin{array}{l}\text { Regulating } \\
\text { Services }\end{array}$} & Climate regulation & $\times$ & $\times$ & $\times$ & $\begin{array}{l}\text { Reflection of radiation as result of } \\
\text { high albedo, latent energy to } \\
\text { absorb heat, carbon sequestration } \\
\text { in permafrost }\end{array}$ \\
\hline & Runoff regulation & $\times$ & $\times$ & $x$ & $\begin{array}{l}\text { Role of natural reservoirs to } \\
\text { modulate seasonal runoff in terms } \\
\text { of reduction in the peak flow and } \\
\text { increase in the minimum flow }\end{array}$ \\
\hline & $\begin{array}{l}\text { Hydrothermal } \\
\text { regulation }\end{array}$ & $\times$ & $\times$ & $\times$ & $\begin{array}{c}\text { Water retention (solid reservoir), } \\
\text { hydrothermal process of } \\
\text { freeze-thaw cycles in soil }\end{array}$ \\
\hline & $\begin{array}{l}\text { Environment } \\
\text { regulation }\end{array}$ & $\times$ & $\times$ & $\times$ & $\begin{array}{l}\text { Retention of contaminants and } \\
\text { facilitation to biogeochemical } \\
\text { process related to organic, } \\
\text { inorganic, and particulate } \\
\text { substances in environment }\end{array}$ \\
\hline \multirow{5}{*}{$\begin{array}{l}\text { Cultural } \\
\text { Services }\end{array}$} & Aesthetic appreciation & $\times$ & $\times$ & $\times$ & $\begin{array}{c}\text { Provision of cryosphere } \\
\text { landscape features for aesthetic } \\
\text { appreciation, sightseeing } \\
\text { pleasure, and inspirational acts }\end{array}$ \\
\hline & Recreational service & $\times$ & $\times$ & $\times$ & $\begin{array}{l}\text { Provision of fields for tourism, } \\
\text { winter sports, and adventure }\end{array}$ \\
\hline & Research & $\times$ & $\times$ & $\times$ & $\begin{array}{c}\text { Provision of evidence of changes, } \\
\text { impacts, adaptation for researches } \\
\text { of the cryosphere }\end{array}$ \\
\hline & Education & $x$ & $\times$ & $\times$ & $\begin{array}{c}\text { Provision or improvement of } \\
\text { environmental knowledge and } \\
\text { awareness about benefits and } \\
\text { hazards in relation to cryosphere, } \\
\text { which affect societies and human } \\
\text { well-being }\end{array}$ \\
\hline & Religion, spirit, culture & $\times$ & $\times$ & $\times$ & $\begin{array}{c}\text { Provision of emotional and } \\
\text { spiritual supports, societal } \\
\text { identities/totems creating } \\
\text { cultural diversity }\end{array}$ \\
\hline \multirow[b]{2}{*}{$\begin{array}{l}\text { Supporting } \\
\text { Services }\end{array}$} & Habitation & $\times$ & $\times$ & $\times$ & $\begin{array}{c}\text { Supporting ecosystem and living } \\
\text { environment }\end{array}$ \\
\hline & $\begin{array}{l}\text { Infrastructure and } \\
\text { engineering }\end{array}$ & - & - & $x$ & $\begin{array}{l}\text { Provision of capacity to sustain } \\
\text { the loading in association with } \\
\text { freeze-thaw stabilization of frozen } \\
\text { ground such as roads, bridges, } \\
\text { building, pipeline, etc. }\end{array}$ \\
\hline
\end{tabular}

Note: " $\times$ " represents the service is relevant. The types of cryosphere services were modified on the basis of the studies summarized by Xiao et al., (2016, 2019) [16,32], Wang et al., (2019) [17], and Su et al., (2019) [33].

The provisioning services include primary benefits of freshwater supply and the potential to provide renewable energy [34,35]. The cryosphere also provides benefits to cryosphere tourism by offering from unique landscapes [36]. Meanwhile, it also acts to regulate climate, runoff [37], environment [38], and regional ecosystems [39], which belong 
to the category of cryosphere regulating services. Cultural services span in a wide domain from tourism and aesthetic to science education and aboriginal culture. "Cryoscape" has been regarded as a broad term for the cryosphere cultural services, but it is not enough to cover the whole context of cultural services [40]. Habitation is a supporting service to maintain the ecosystem. The infrastructure and engineering service supported by frozen grounds are considered a part of the support services [41].

\subsection{Development of Relationship between Cryosphere Services and SDGs}

Human well-being can benefit from natural resources, both directly and indirectly [42]. The cascade effect of cryosphere services in achieving the SDG targets is considered in an approach in the Guidance Note for Lead Authors of the IPCC Fifth Assessment Report on Consistent Treatment of Uncertainties [43]. Meanwhile, the literature-based approach [44] was applied to substantiate the understanding of what benefits can be obtained from cryosphere services directly or indirectly and their link to SDGs. As demonstrated in Table S5 in the Supplementary Materials, it details the chain of causal effects from all services to 62 SDG targets. The indirect contribution of services to the targets can be made by cascading effects through a chain of interactions from the services ending up at the targets. The literature was attained from the database of Web of Science and research reports of the cryosphere and sustainable development, including IPCC AR5, SROCC, ICIMOD, etc. The search of that literature was based on the keywords included in each SDG target, and relevant words in the abstracts when none were identified by the keywords.

Direct or indirect interlinkage between services and SDG targets depends on the cascading effect that occurs directly on targets or via other factors. Specifically, the cryosphere services directly affects the targets in the cascading process, while possibly indirectly affecting the specific targets. This is based on the evidence identified in the critical review of hundreds of publications. The literature was employed to substantiate the understanding about what benefits can be obtained from cryosphere services directly or indirectly and their link to SDGs, with details demonstrated in the Supplementary Materials Table S5. The significance of direct and indirect linkage depends on how important the services are to the pathway impacting the targets, and is indexed at three levels, i.e., strong, weak, and none, or valued by $1,0.5$, and 0 , respectively. In this regard, the synergies and tradeoffs between SDG targets [30] may considerably affect the network structure that determines roles of services in contributions to the SDG targets. The strength of interconnections is represented by the strong and weak types [29], described as 1 and 0.5, similar to the interconnections among services and SDG targets. As a result, the relationship of 12 cryosphere services (aesthetic and recreational, research and education combined) with 15 SDGs and 62 corresponding targets can be established, as described in Table S1 in the Supplementary Materials.

\subsection{The Network of the Cryosphere Services in Achieving the SDGs}

Network analysis can be applied to analyze the topology and dynamics of networks $[45,46]$. The approach is normally applied in the graph theory to graphically arrange all nodes in a way that optimizes modularity to balance the relevance between each node [47]. The centrality and layout structure of the network are important to illustrate the inherent complexities of the cryosphere services in achieving the SDGs. The corresponding layout and topology can be developed on the basis of attractions and repulsions between nodes (services and targets, targets and targets) along with edges (strong and weak linkage). In the network, there are linkages between 14 services and 62 targets (Table S1 in the Supplementary Materials), in addition to the linkage among SDG targets. A matrix has been applied to detail the linkage of SDG targets, provided in the reference [29]. As a result, we can unravel the criticality of services in terms of their centrality in contribution to SDGs in the network. By looking into the network modularity, we can further unveil the specificity of services that could potentially make co-contributions appertaining to the clusters of SDG targets. 
In more detail, the eigenvector centrality is to evaluate the influence of each node in a network [48]. The importance (degree) of the nodes depends on the weight and number of neighbors. The eigenvector centrality in networks, $x_{i}$, is:

$$
\mathrm{EC}(\mathrm{i})=\mathrm{x}_{\mathrm{i}}=\mathrm{c} \sum_{\mathrm{j}=1}^{\mathrm{n}} \mathrm{A}_{\mathrm{ij}} \mathrm{x}_{\mathrm{j}}
$$

where $c$ is the proportional constant, $x=\left[x_{1}, x_{2}, x_{3}, \cdots, x_{n}\right]^{T}$, and $T$ is the matrix transpose. $\mathrm{A}_{\mathrm{ij}}$ is the adjacency matrix assigned by the score of adjacent nodes $\mathrm{x}_{\mathrm{j}}$ in the network. $\mathrm{A}_{\mathrm{ij}}=1$ means there is a link between nodes $\mathrm{x}_{\mathrm{i}}$ and $\mathrm{x}_{\mathrm{j}}$, and zero otherwise. $\mathrm{x}$ is the eigenvector corresponding to the eigenvalue $c^{-1}$ of the matrix $A$. The eigenvector centrality of cryosphere services does not merely count how many targets are linked, but it also considers the degree of those targets. The Force-Directed Layout algorithm is based only on information contained within the structure of the graph itself rather than relying on contextual information. Repulsion force $\mathrm{F}_{\mathrm{r}}$ relies on the attraction and repulsion force for network spatialization [47] as follows:

$$
\mathrm{F}_{\mathrm{r}}\left(\mathrm{x}_{1}, \mathrm{x}_{2}\right)=\mathrm{k}_{\mathrm{r}} \frac{\left(\operatorname{deg}\left(\mathrm{x}_{1}\right)+1\right)\left(\operatorname{deg}\left(\mathrm{x}_{2}\right)+1\right)}{\mathrm{d}\left(\mathrm{x}_{1}, \mathrm{x}_{2}\right)}
$$

where deg $(x)$ represent the degree of the nodes; the $(\mathrm{deg}+1)$ of the two nodes has more impact on the result and its readability than the (attraction, repulsion) model [47]; $d\left(\mathrm{x}_{1}, \mathrm{x}_{2}\right)$ is the distance of the nodes; the coefficient $\mathrm{k}_{\mathrm{r}}$ is defined by the settings to adjust the scaling of the network.

Meanwhile, the modularity is used to organize and cluster the network topology structure [49]. The community modularity algorithm measures the quality of the partitions and the resolution limit in community detection [50]. The Newman-Girvan algorithm (2004) for discovering the modules of a network consists in optimizing modularity with the largest value Q [51]. Cryosphere services that influence the SDGs are directed and weighted networks. It has been proposed to account for the directionality of the links summarized as follows:

$$
Q=\frac{1}{2 m} \sum_{C \in P} \sum_{i, j \in C}\left[A_{i j}-\frac{k_{i}^{\text {in }} k_{j}^{\text {out }}}{2 m}\right]
$$

where $\mathrm{k}_{\mathrm{i}}=\sum_{\mathrm{j}} \mathrm{A}_{\mathrm{ij}}$ are the sum of the weights of the degrees of the vertices attached to vertex $x_{i}, k_{i}^{i n}=\sum_{j} A_{i j}$ is the sum of the weights of the links from $x_{i}$ to nodes in community $C$ and $\mathrm{k}_{\mathrm{j}}^{\text {out }}=\sum_{\mathrm{j}} \mathrm{A}_{\mathrm{ji}} \cdot \mathrm{m}=\sum_{\mathrm{ij}} \mathrm{A}_{\mathrm{ij}} / 2$ is the sum of the weights of all the links in the network.

Meanwhile, the resolution limit of modularity imposes a limit on the size of the smallest community one can obtained by modularity optimization [50]. The change in modularity $\Delta Q$ to identify the efficiency results of algorithm is as follows [52]:

$$
\Delta \mathrm{Q}=\left[\frac{\sum_{\mathrm{in}}+2 \mathrm{k}_{\mathrm{i}}^{\mathrm{in}}}{2 \mathrm{~m}}-\left(\frac{\sum_{\mathrm{tot}}+\mathrm{k}_{\mathrm{i}}}{2 \mathrm{~m}}\right)^{2}\right]-\left[\frac{\sum_{\mathrm{in}}}{2 \mathrm{~m}}-\left(\frac{\sum_{\mathrm{tot}}}{2 \mathrm{~m}}\right)^{2}-\left(\frac{\mathrm{k}_{\mathrm{i}}}{2 \mathrm{~m}}\right)^{2}\right]
$$

where $\sum_{\text {in }}$ is the sum of the weights of the links inside a community. $\sum_{\text {tot }}$ is the sum of the weights of the links incident to edges in the community. $\mathrm{m}$ is the sum of the weights of all the links in the network. With the community detection algorithm, diagnostic models are obtained by moving an isolated node $i$ into $j$. The comparison standard value of the resolution is 1 . The smaller the resolution, the more communities, and vice versa, while the modularity optimization might miss important substructures of a network. 


\section{Results}

\subsection{First-Pass Assessment of Relationship between the Cryosphere Services and SDGs}

Similar to the MA framework, the cryosphere services can generally be divided into provisioning, regulating, cultural, and supporting services. As described in the method, in this study, the provisioning services includes freshwater, clean energy, snow and ice material; the regulating services contains climate regulation, runoff regulation, environment regulation, and hydrothermal regulation; the cultural services involve aesthetic and recreational, research and education, and religion, spirit, culture; and the supporting services covers habitation, infrastructure and engineering. Among all SDGs, we considered SDGs 1-15 in association with the services. For SDG 16 and 17 that aim to ensure 'peace, justice and strong institutions' and 'partnerships for the goals', respectively, we regard them mostly in alignment with the levers [30] that ensure the transformation pathways to meet the goals.

We established a relationship dataset in association with the linkages between the cryosphere services and SDGs, based on the evidence identified in the critical reports and literature (see Method). It was carried out by an approach to follow the chain of causal effects from cryospheric resources to the perspective services which are beneficial to high mountain societies and in turn influence or contribute to SDGs. The contribution is either direct and/or indirect, categorized as strong, weak, or unrelated, and identified through the assessment of its role that is a main driver or not.

By integral analysis of the goals, there are sixty-two targets linked to the services, either directly or indirectly, which is depicted in Figure 1, with relevant relationship details described in Table S1 in the Supplementary Materials. The ubiquity of the cryosphere services and its inherent multiple connection with SDGs in high mountains determine the complex relationship. Individual goals can be influenced by multiple services, while a single type of service has contributions to multiple goals.

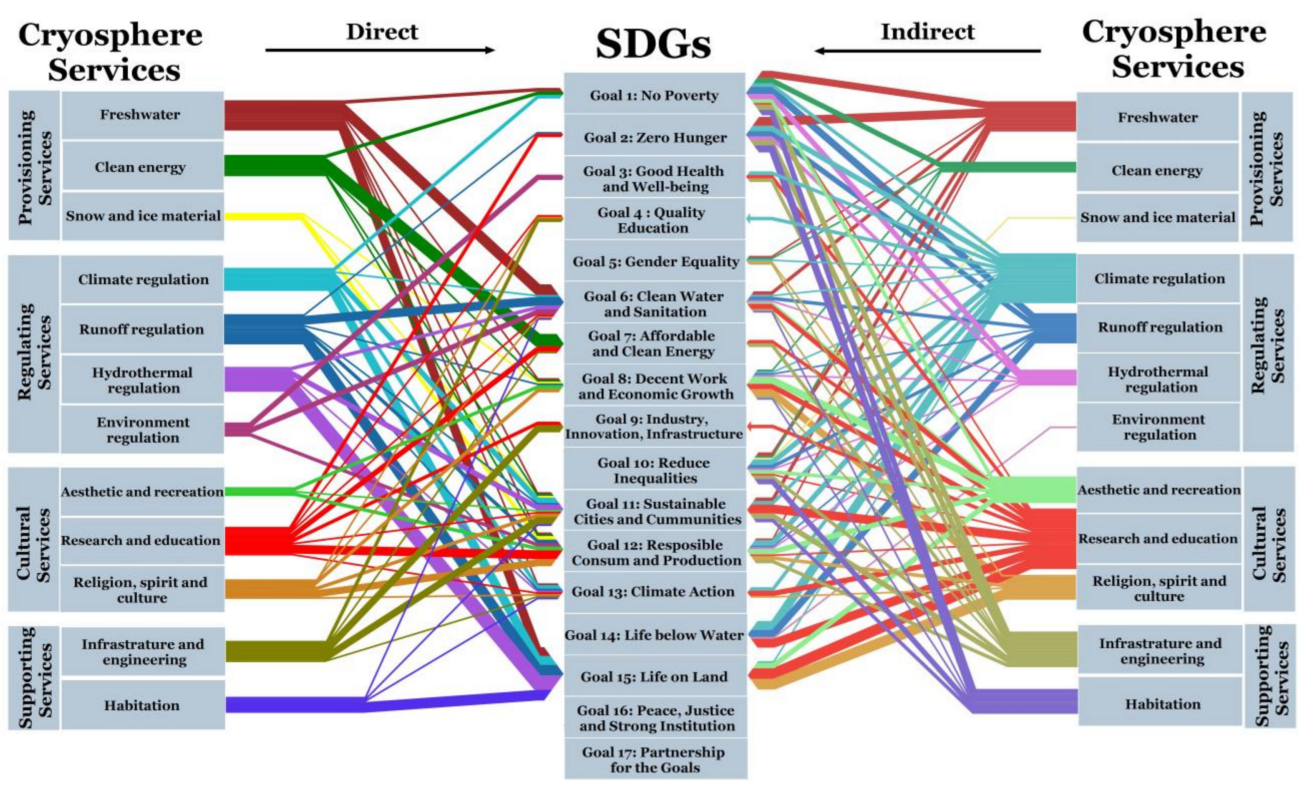

Figure 1. Direct and indirect contributions of the cryosphere services to SDGs. The thickness of lines represents the degree of contributions of a service to a specific goal by summarizing the degree of contributions on all targets pertinent to the goal. The SDGs contributed to by the services in order of significance are SDGs 1, 2, 6, 11, 12, and 15; for direct contribution, they are SDGs 6, 7, 11, 12, and 15; for indirect contribution, they are SDGs 1,2, 8, 10,11,12,14, and 15. SDGs 16 and 17 are regarded as the goals to ensure the transformation to meet all goals.

We found that some SDGs are more prominently influenced by cryosphere services (in order), including those to ensure 'no poverty' (SDG 1), 'zero hunger' (SDG 2), 'clean 
water and sanitation' (SDG 6), 'sustainable cities and communities' (SDG 11), 'responsible consumption and production' (SDG 12), and 'life on land' (SDG 15). There are also services distinctly important to the goals, such as clean energy in the provisioning services that has a direct influence on 'affordable and clean energy' under SDG 7, in addition to the 'freshwater' service in SDG 6 and SDG 15. In this regard, the services are essentially pivotal to maintain the most basic needs of societies as well as environment in high mountains. Globally, the significance is particularly reflected in the arid regions, such as the areas with irrigation from mountain meltwater [53].

In contrast, the cultural and supporting services show more indirect contributions to the goals, and demonstrate broad influences on SDGs. For example, 'research and environmental education' are indirectly linked to a wide range of SDGs. Therefore, harnessing their full potential could effectively improve a broad spectrum of SDGs, which has not yet been appreciated and should be greatly enhanced in the development of high mountains.

It should be mentioned that 'climate regulation', a part of cryosphere regulation services, also contributes to the SDGs on a considerably broad perspective covering 33 of 169 targets and 13 of 17 SDGs, and it is deteriorating as a result of global warming. While the pursuit of SDGs in high mountains is a regional issue, the fundamental solutions to curb or slow the services deterioration, such as climate regulation, hinge on global mitigation of climate change to some extent. This implies that a regional implementation to attain SDGs in high mountains would become more difficult without involving global efforts to alleviate climate change.

The significance of services contributions to SDGs can be categorically summarized by an index related to provisioning, regulating, culture, and supporting services, as shown in Figure 2. The regulating and cultural services have more influence on SDGs than the other two in general. This once again reflects the effects of indirect contributions that may lead to a broad impact. Meanwhile, the provisioning services provides the most significant contributions to SDG 1, SDG 6, and SDG 7, and the supporting services mostly matters to SDG 1, SDG 2, and SDG 11. In addition, the regulating services shows a strong presence in both direct and indirect contributions to SDGs, despite their different preference. In general, the provisioning and supporting services offer more direct contributions while the regulating and culture services deliver more indirect contributions.

The significance of cryosphere services to SDGs as well as the dependence of SDGs on the cryosphere services prevail in the assessment, but the understanding of their criticality and specificity to SDG targets in this complex relationship would be even more crucial in advancing SDGs when they are intended to fully take the advantage of key services in high mountains. It is worth bearing in mind that there are interconnections, not only between services but also among SDG targets. Without this consideration, the impact of services on SDGs cannot be fully understood.

\subsection{Centrality and Specificity of the Cryosphere Services to SDG Targets}

We now apply a network to more precisely represent the relationship between the cryosphere services and interconnected SDG targets. For a network, the eigenvector centrality can measure the criticality of the cryosphere services to represent the significance of their contribution to SDG targets in a systematic view. The centrality can also quantify the SDG targets to depict the degree of their dependence on the services. The network can be structured by the force-directed layout based on the established relationship. Basically, the communities of network separate services and SDG targets into modules or clusters. In the same community, the services display a similarity concerning their roles of contributions to SDG targets (more details in Method). The co-contribution may then rise as to the services beneficial to the same cluster of SDG targets, which leads to the specific nature of the services. In the meantime, the services that relatively take more roles to support SDG targets would be represented by their position closer to the center of network, while those taking fewer roles are located on the periphery. 


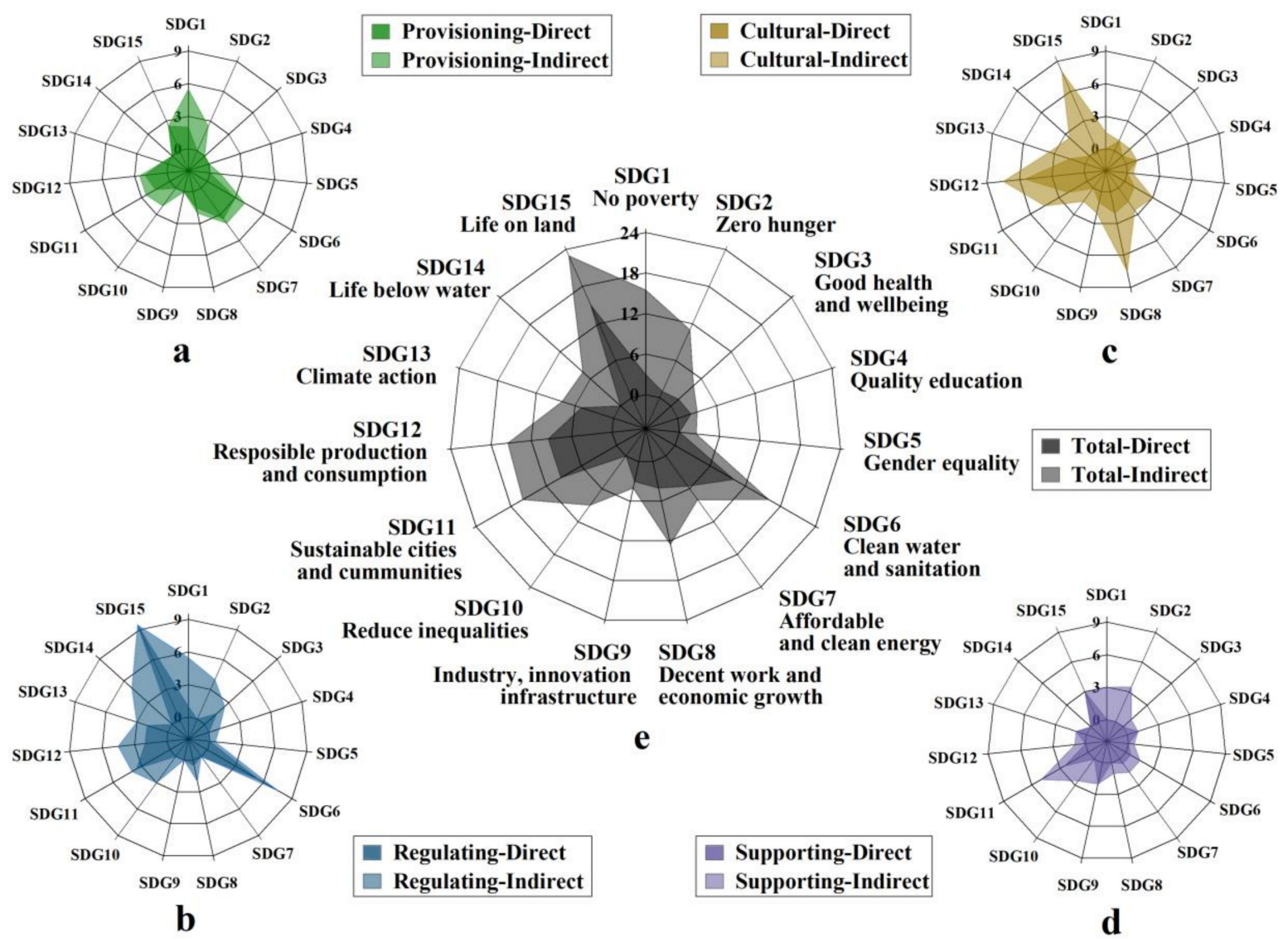

Figure 2. Significance of cryosphere services' contribution to SDGs, in terms of provisioning, regulating, cultural, supporting services, and their total. Their overall significance for each goal is summarized by the contributions to all targets pertinent to the goal, and stacked with direct and indirect contributions in the dark and light color, respectively, in the diagrams: (a) Significance of provisioning services, presenting that SDG 1 benefits the most from the total or indirect contributions of the services, whilst SDG 6 and SDG 7 obtain the most from direct ones; (b) contributions to SDGs by regulating services, suggesting that SDG 6 and SDG 15 prevail by the benefits from direct contributions, and SDG 1 benefits the most from indirect ones; (c) contributions to SDGs by cultural services, implying that SDG 8 and SDG 15 are mostly affected by indirect contributions, and SDG 12 benefits the most from direct ones; (d) contributions to SDGs by supporting services, illustrating that SDG 2 is mostly affected by the benefits from indirect contributions, and SDG 15 benefits the most from direct ones. (e) contributions to SDGs by total cryosphere services, illustrating that SDG 15 are mostly affected by the benefits from indirect contributions, and SDG 1 benefits the most from direct ones.

As results show in the network (Figure 3), 'research and environmental education', 'climate regulation', 'runoff regulation', and 'freshwater' possess the centrality in the first four highest among all services (Table 2). This thus suggests that they take a central role in contributions to the SDGs targets in high mountains, which is consistent with the early results. In addition, the SDG targets also exhibit the character of centrality, which reflects on how critically they rely on the services. As shown in Table S2 in the Supplementary Materials, 'sustain economic growth with national circumstances' (target 8.1), 'protect the cultural and natural heritage' (target 11.4), 'sustainability of terrestrial and inland freshwater ecosystems' (target 15.1), 'ensure the conservation of mountain ecosystems' (target 15.4), 'reduce the degradation of natural habitats' (target 15.5), 'protect and restore water-related ecosystems' (target 6.6), and 'sustainable management and efficient use of natural resources' (target 12.2) have the highest eigenvector centrality in the network. 


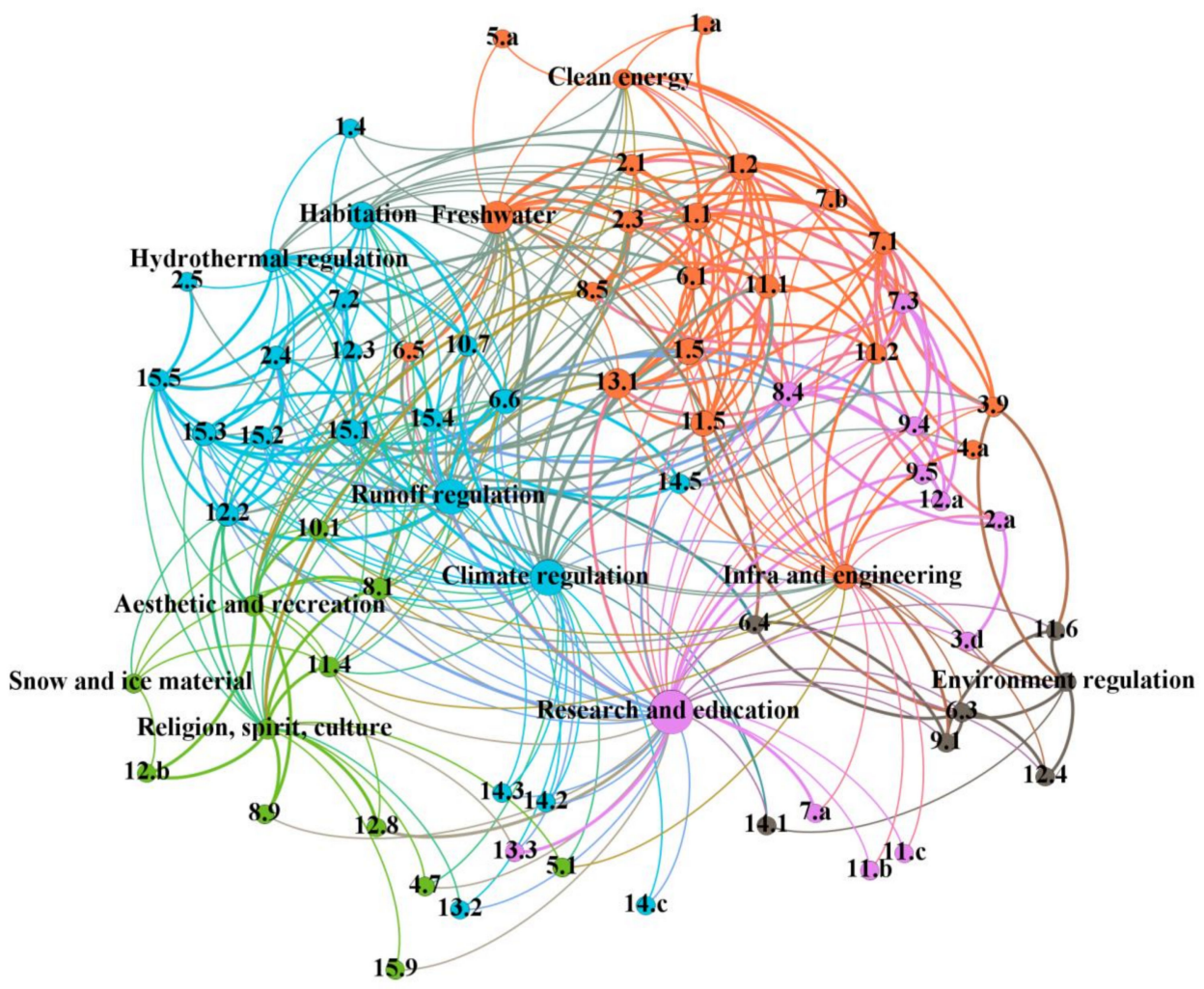

Figure 3. The network of cryosphere services and SDG targets in numbers. The scale of the dots represents the eigenvalue centrality, and the color represents the communities. The locations of the services and targets in the network to some extent implies that their role is more central when they are in the center of the graph or less central when they are in the peripheral area. The network takes into account all relations between services and targets, and it encompasses five communities with the resolution of 1 and the modularity of 0.292 . The service centrality indicates that research and education (1.00), climate regulation (0.947), runoff regulation (0.946), and freshwater (0.896) are the top four above 0.85 to take critical roles in supporting SDGs. The services embraced in the communities are (1) 'research and education', (2) freshwater, clean energy, and 'infrastructure and engineering', (3) runoff regulation, climate regulation, hydrothermal regulation, and habitation, (4) 'religion, spirit, culture', 'aesthetic and recreation', and 'snow and ice material', and (5) environment regulation.

Table 2. The eigenvector centrality of cryosphere services.

\begin{tabular}{ccc}
\hline \multicolumn{2}{c}{ Cryosphere Services } & Eigenvector Centrality \\
\hline \multirow{3}{*}{ Provisioning services } & Freshwater & 0.896 \\
& Clean energy & 0.389 \\
& Snow and ice material & 0.128 \\
\hline \multirow{3}{*}{ Regulating services } & Runoff regulation & 0.947 \\
& Climate regulation & 0.947 \\
& Ecological regulation & 0.603 \\
& Environmental regulation & 0.117 \\
\hline \multirow{2}{*}{ Cultural services } & Research and education & 1.000 \\
& Aesthetic and recreation & 0.432 \\
& Religion, spirit, culture & 0.439 \\
\hline \multirow{2}{*}{ Supporting services } & Infrastructure and & 0.704 \\
& engineering & 0.794 \\
\hline
\end{tabular}


While Figure 3 strengthens the views reflected in the first-pass assessment, it stands out with five communities in the network that also take into account the interconnection of SDG targets. They highlight the specificity of the services with regard to their co-contributions to the cluster of SDG targets in each community. Among three of the most outstanding communities, one is dominated by co-contribution of 'freshwater', 'clean energy', and 'infrastructure and engineering' service to the cluster of 18 targets out of 62 in total in the network, and delivers benefits towards a broad spectrum of SDGs on land, indicating its cruciality in developing sustainability in high mountains. The community prevailing with the regulation services in runoff, climate, and hydrothermal processes, together with closely associated habitation, also includes 18 targets of total 62 . This strongly benefits the targets pertinent to life on land of SDG 15 and further benefits the eradication of hunger in SDG 2, and demonstrates their co-contribution to the environment and subsequent benefits to high mountain communities. 'Research and education' is the service that possesses the highest centrality among all services and relatively stands alone, but it takes a more broad role to support the targets mostly clustered in other communities. In this regard, to advance the SDGs in high mountain regions, it is fundamental to enhance the effort to take advantage of high mountain scientific evidence and foster new knowledge, which enables SDG implementation from practical actions to policies.

Relatively fewer roles, but not considered to be trifling, are taken by the network community that covers more intangible services, particularly related to cultural services. For instance, the community of the 'religion, spirit, culture', 'aesthetic and recreation', and 'snow and ice material' are associated with cryosphere tourism to provide the pathway to the benefit of the sustainable tourism targets. However, the potential roles of cultural services are weakened by less clarity of the cultural services about its relationship with the SDG targets, as well as potentially by a lack of coverage of SDG targets in the domain for high mountain societies. In this regard, more assessment of SDG targets in relation to high mountain culture and religions should be specifically considered before the effort to gain more insights into the roles of culture services to support SDG targets.

\subsection{Cryosphere Services to SDG Targets in SEPS}

The GSDR 2019 provides a detailed overview of the dimensions of the six entry points and the main aspects as shown in Table S3. The sixty-two targets affected by cryosphere services contain human needs, economy, agriculture, energy, and society and ecology dimensions corresponding to the six entry points (Table S3 in the Supplementary Materials). Based on the network established earlier, the cryosphere services along with the targets divided into six social networks in association with SEPs (Figure 4) and the centrality of services in each SEP can be calculated as shown in Table 3.

This shows that SEP 1, strengthening human well-being and capabilities, depends on all services in high mountains, in particular those in community 2 and 3 in the network that capture the provisioning and regulating services in addition to the 'research and education' service. Meanwhile, based on the centrality from network analysis (Table S4 in Supplementary Materials), the transformation through the services to strengthen human well-being and capabilities for SDGs is centered on the achievement of target 1.1 (eradicate extreme poverty for all), target 1.2 (reduce poverty in all dimensions), target 1.5 (build the resilience to reduce the exposure and vulnerability), and target 11.5 (reduce the disasters and economic losses), which are all related to the basic needs of societies. In other words, the theme of broad services in the cryosphere has to be developed to ensure advancement towards this SEP in high mountains. The pathway to meet the transformation for SEP 1 has to be integrated through better governance in cryosphere nature resource management. This involves meltwater for provisioning services and cryospheric environmental conservation (land use changes in particular) for regulation services, financing economic development to maximize the benefit of clean energy and infrastructure and engineering services, engagement of individual and collective actions that embrace local culture and 
religion, and ineluctably, investment in science and technology empowering education and the knowledge on all aspects above.

SEP 2, shifting towards sustainable and just economies, also relies on all services. Based on the centrality in the network, the services are instead centered on the target 8.1 (sustain per capita economic growth), target 12.2 (sustainable management and efficient use of natural resources), target 11.5 (reduce the disasters and economic losses), and target 8.4 (improve global resource efficiency in consumption and production). In this regard, it is not a surprise that the pathway to meet the transformation for SEP 2 inclines more to the theme of science and education service in community 1 of the network. It is essential to the lever of science and technology, by which to identify the balance between cryospheric natural resource consumption and economic development. Similar to SEP 1, the regulation services in community 2 are crucial for the transformation in high mountains, which maintains the inhabitation for ecosystems as well as mountain societies.

SEP 3, building food systems and healthy nutrition patterns, hinges more specifically on the provisioning and regulating services in the cryosphere. The centrality in the network indicates that the services are centered at the target 2.1 (end hunger of all), target 2.3 (improve the agricultural productivity and incomes), and target 2.4 (sustainable food production systems). The lever to enable the pathway to transformation relies on the governance in the theme to manage the services provided by freshwater and runoff regulation, with an emphasis at local and regional scales on building resilience and sustainability in agriculture or global scale on climates.

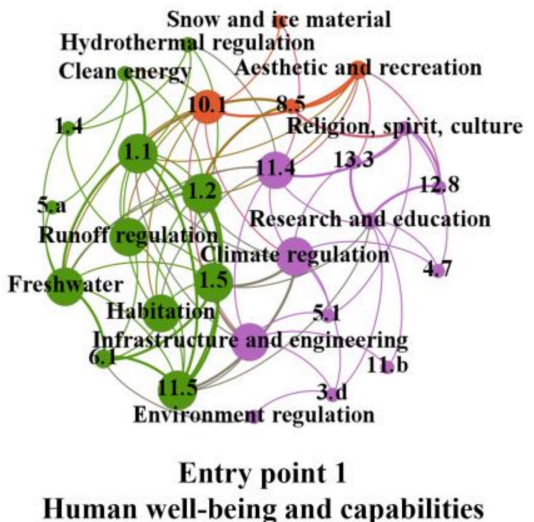

Human well-being and capabilities

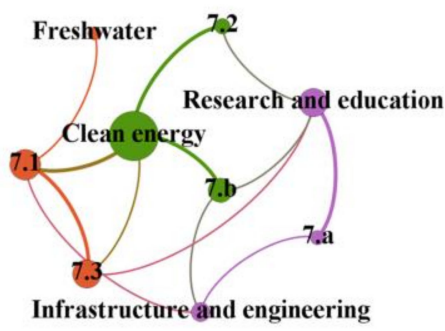

Entry point 4

Energy decarbonization and universal access

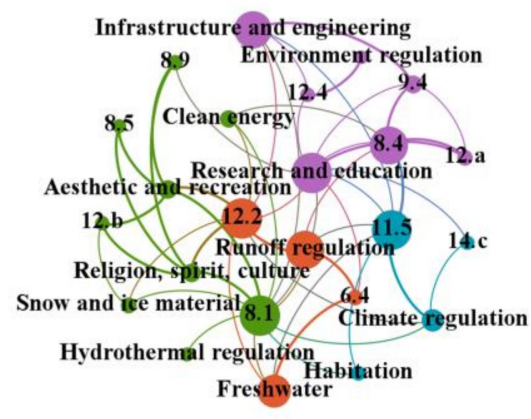

Entry point 2

Sustainable and just economies

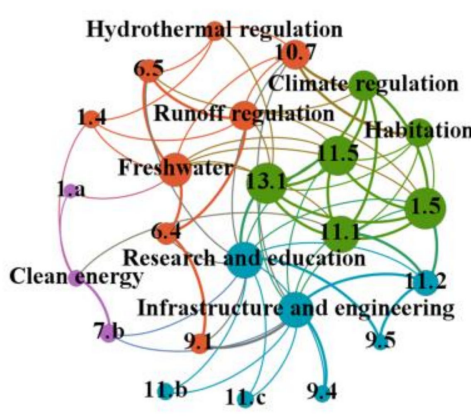

Entry point 5

Urban and peri-urban development

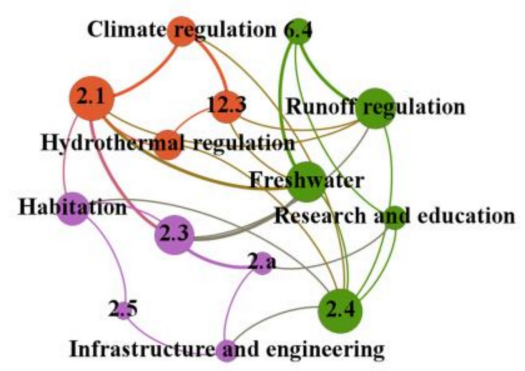

Entry point 3

Food systems and nutrition patterns

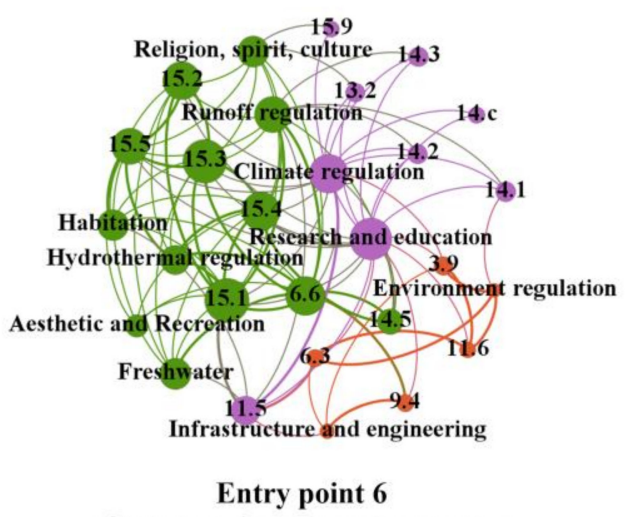

Global environmental commons

Figure 4. Network analysis of the cryosphere services and SDG targets with respect to the six entry points. The dot scale and colors represent the centralities and modularity of the cryosphere services to the targets, respectively. The resolution is 1 and the modularity of entry point 1 is 0.265 , entry point 20.353 , entry point 30.241 , entry point 40.218 , entry point 50.310 , and entry point 60.270 . 
Table 3. The eigenvector centralities of services in six entry points (SEPs) grouped in five communities as shown in Figure 3.

\begin{tabular}{|c|c|c|c|c|c|c|c|}
\hline $\begin{array}{l}\text { Network } \\
\text { Community }\end{array}$ & $\begin{array}{l}\text { Cryosphere } \\
\text { Services }\end{array}$ & $\begin{array}{c}\text { SEP 1 } \\
\text { Strengthen } \\
\text { Human } \\
\text { Wellbeing and } \\
\text { Capabilities }\end{array}$ & $\begin{array}{c}\text { SEP } 2 \\
\text { Shift Towards } \\
\text { Sustainable } \\
\text { and Just } \\
\text { Economies }\end{array}$ & $\begin{array}{c}\text { SEP } 3 \\
\text { Build Food } \\
\text { Systems and } \\
\text { Healthy } \\
\text { Nutrition } \\
\text { Patterns }\end{array}$ & $\begin{array}{c}\text { SEP 4 } \\
\text { Achieve Energy } \\
\text { Decarboniza- } \\
\text { tion and } \\
\text { Universal } \\
\text { Access to } \\
\text { Energy }\end{array}$ & $\begin{array}{c}\text { SEP } 5 \\
\text { Promote } \\
\text { Urban and } \\
\text { Peri-Urban } \\
\text { Development }\end{array}$ & $\begin{array}{c}\text { SEP 6 } \\
\text { Secure Global } \\
\text { Environmental } \\
\text { Commons }\end{array}$ \\
\hline 1 & $\begin{array}{l}\text { Research and } \\
\text { education }\end{array}$ & 0.45 & 0.97 & 0.42 & 0.87 & 0.85 & 0.93 \\
\hline \multirow{3}{*}{2} & Freshwater & 0.75 & 0.54 & 0.89 & 0.28 & 0.75 & 0.62 \\
\hline & $\begin{array}{l}\text { Clean energy } \\
\text { Infrastructure }\end{array}$ & 0.37 & 0.46 & * & 1.00 & 0.20 & * \\
\hline & $\begin{array}{l}\text { and } \\
\text { engineering }\end{array}$ & 0.71 & 0.61 & 0.37 & 0.70 & 0.82 & 0.14 \\
\hline \multirow{4}{*}{3} & $\begin{array}{l}\text { Runoff } \\
\text { regulation }\end{array}$ & 0.73 & 0.66 & 0.89 & * & 0.61 & 0.76 \\
\hline & $\begin{array}{l}\text { Climate } \\
\text { regulation }\end{array}$ & 0.75 & 0.52 & 0.59 & * & 0.64 & 0.84 \\
\hline & $\begin{array}{l}\text { Hydrothermal } \\
\text { regulation }\end{array}$ & 0.37 & 0.18 & 0.59 & * & 0.30 & 0.56 \\
\hline & Habitation & 0.69 & 0.31 & 0.69 & * & 0.58 & 0.62 \\
\hline \multirow{3}{*}{4} & $\begin{array}{l}\text { Religion, spirit, } \\
\text { culture }\end{array}$ & 0.24 & 0.48 & * & * & * & 0.61 \\
\hline & $\begin{array}{l}\text { Aesthetic and } \\
\text { recreation }\end{array}$ & 0.50 & 0.48 & * & * & * & 0.37 \\
\hline & $\begin{array}{l}\text { Snow and ice } \\
\text { material }\end{array}$ & 0.16 & 0.39 & * & * & * & * \\
\hline 5 & $\begin{array}{l}\text { Environment } \\
\text { regulation }\end{array}$ & 0.10 & 0.05 & * & $*$ & * & 0.11 \\
\hline
\end{tabular}

Note: "*" means that there is a lack of evidence that can be identified.

SEP 4, achieving energy decarbonization and universal access to energy, emphasizes global needs in a sustainable and equitable manner in the future while minimizing the impact on the environment. In the network, the action of services is centered on the target 7.1 (ensure universal access to energy), target 7.3 (improve energy efficiency), and target 7.b (expand infrastructure and upgrade technology for energy). The hydropower to supply clean and affordable energy is the key service for the pathway to transformation, urging investment in infrastructure. The services of research and education, and infrastructure and engineering are meanwhile indispensable to support these targets. Hydropower becomes increasingly more important for the transformation to reinforce the world-wide campaign of net-zero $\mathrm{CO}_{2}$ emission, without compromising the effort to eradicate poverty (SDG 1) and have zero hunger (SDG 2) in high mountains.

SEP 5, promoting urban and peri-urban development, is centered on target 1.5 (build the resilience in vulnerable situations), target 11.1 (access to adequate, safe and affordable housing), target 11.5 (reduce the disasters and economic losses), and target 13.1 (strengthen resilience and adaptive capacity to hazards and disasters). The services for the transformation are dominated by those related to 'infrastructure and engineering' as well as the provisioning of meltwater, with the vital supports from 'research and education'.

SEP 6, securing global environmental commons, is centered on SDG 15 of life on land, including target 15.1 (conservation of freshwater ecosystems and their services), target 15.3 (combat desertification, restore degraded land and soil), target 15.4 (ensure the conservation of mountain ecosystems), target 15.2 (promote the implementation of sustainable management of all types of forests), and target 15.5 (take actions to reduce the degradation of natural habitats). Once again, the services that support inhabitation, including climate and runoff regulation as well as freshwater, are pivotal to the transformation for ecological conservation and restoration, which is substantiated by research and education. 


\section{Discussion}

Multi-scale interlinkages between cryosphere services and SDGs help us to clarify the services in realizing the SDGs from the cryosphere perspective. The specificity of services' contributions to SDG targets is represented by modularity to some extent. Results show five communities in the network with each revealing a distinction in contributing to a cluster of SDG targets in the same community. One community, including 'freshwater', 'clean energy', and 'infrastructure and engineering', delivers benefits towards a broad spectrum of SDGs on land involving 16 targets. In another community, runoff and climate as well as hydrothermal regulating services emphasize life on land and hunger eradication in mountain communities. Parallel to two major communities in the network, the service for 'research and education' takes vital roles to support the processes in other communities. In this regard, the implementation strategies of SDGs in high mountains can be targeted by virtue of the cryosphere services. Moreover, the 15 SDGs, 62 targets, and corresponding indicators constitute the basic framework of cryosphere services to sustainable development. Although SDG targets are represented by comprehensive indicators covering a wide range of human basic needs, environment, economy, and society, the quantification of indicators is more focused on the assessment of SDGs related to the economy [27]. As seen in alignment with the SEPs, specific pathways and corresponding indicators can be identified for the quantitation of cryospheric services to meet the multi-dimensional SDGs in high mountains.

As so far, we generally elucidate the roles of the cryosphere services in supporting SDGs in high mountains, but the interaction among services may compound their contributions. In fact, the services can be considered as the benefit obtained from the use of cryospheric natural resources, which are preserved as stocks, such as glaciers, snow cover, and frozen ground, or flows mainly in meltwater. The increase in services depending on stocks may compromise other services relying on flows, and vice versa. As a result, tradeoffs may emerge. It is worth mentioning that global warming can be in favor of the services depending on flows in a short term, while subduing others relying on stocks [54]. For example, increasing meltwater can cause an increase in freshwater supply and associated services [55-59], while reducing the capacity of the cryosphere to regulate climate [60].

By dividing services into three categories depending on either 'stocks', 'flows', or both as indicated in Figure 5, we can identify the tradeoffs between and within services. Between services, ones related to clean energy and freshwater and runoff regulation would compete with those related to climate regulation, environmental regulation, infrastructure and engineering, snow and ice materials, and also with 'sub-services' of the services that have a mixed dependence on stocks and flows, such as hydrothermal regulation, aesthetic and recreation, religion, spirit, culture, research and education, and habitation. The tradeoffs could also happen between sub-services within the services pertinent to both stocks and flows. By looking into the SDG targets in relation to the services (see Table S1 in Supplementary Materials), as shown in Figure 5, the services (including sub-services) that depend on flows in the cryosphere would have contributions more relevant to the targets in SDG 5, 6, and 7, while those depending on stocks would have contributions leaning more towards the targets in SDG 3, 4, 8, 9, 11, 12, and 13. Generally, both of them have effects on SDG 1, 2, 10,11, 14, and 15.

It is important to understand the tradeoffs and synergies among cryosphere services in the SEPs, as they would impact the transformation to meet SDGs in high mountains. The establishment of pathways needs to take into account the interlinkage effect between the services. The approach is to ensure the effectiveness of the pathway implementation in terms of four levers (governance, economy and finance, individual and collective action, and science and technology) [30], which are associated with the means of implementation characterized of SDG 16 (peace, justice, and strong institutions) and 17 (partnerships for the goals). As for the stakeholder (practitioners, policymakers, scientists, etc.), the coordination among SEPs and four levers can be useful to promote the optimal allocation of cryosphere resources and enhance the adaptability to climate changes. 


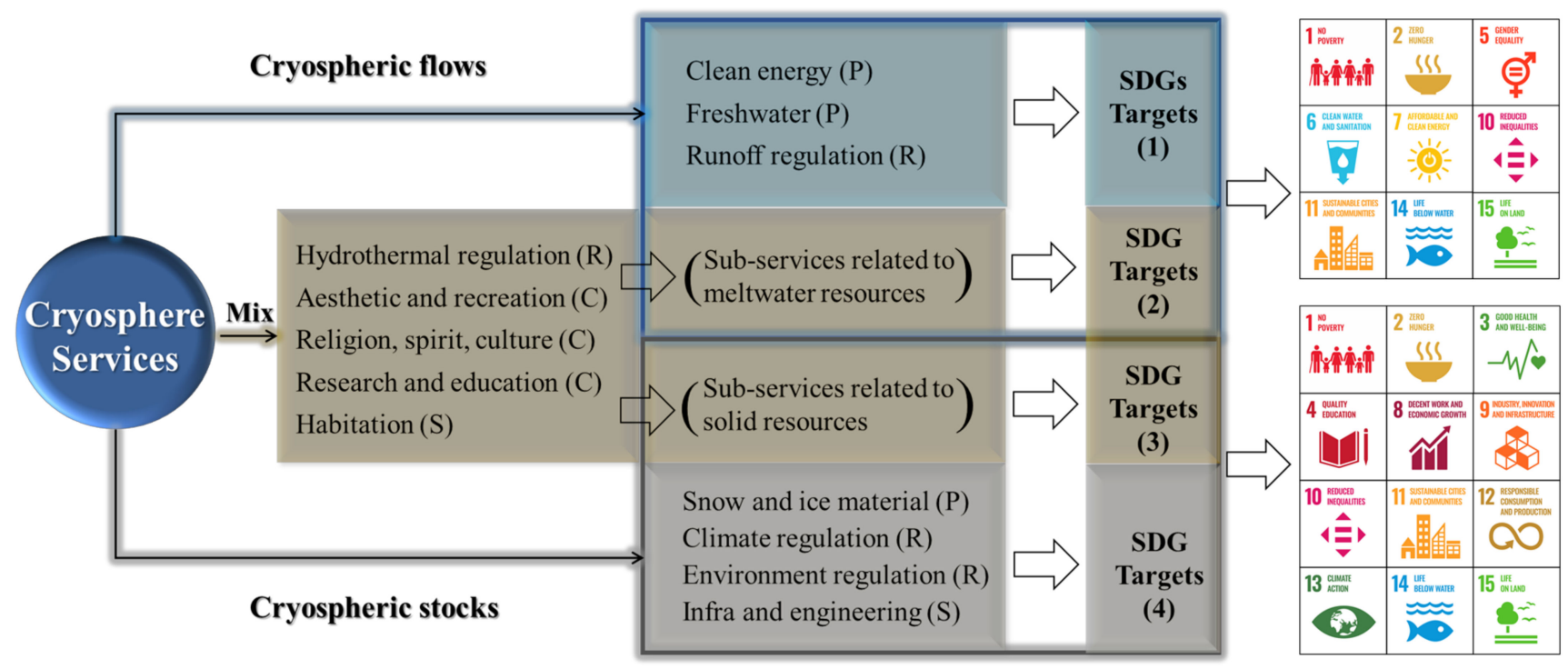

Sub-services related to cryospheric flows
Hydrothermal regulation (melting and endothermic process)
Aesthetic and recreation (landscape, sightseeing related to meltwater)
Research and education (meltwater changes, impacts, adaptation research
and environment related education and awareness)
Religion, spirit, culture (emotional spiritual, cultural identity features
attached to river, ice lake, etc.)
Habitation (meltwater and related environment)

\section{Sub-services related to cryospheric stocks}

Hydrothermal regulation (freezing and exothermic process) Aesthetic and recreation (landscape, winter sports,etc)

Research and education (cryosphere changes, impacts, adaptation

research and environment related education and awareness)

Religion, spirit, culture (emotional spiritual, cultural identity features attached to snow mountain, etc.)

Habitation (low temperature and frozen environment)

Figure 5. The services rely on either stocks, flows, or both, represented by three colors. The types of services include P: provisioning, R: regulating, C: cultural, and S: supporting. The potential synergy in the contributions of services to SDGs may occur for those that share stocks or flows, while tradeoffs may emerge for those that depend on stocks and flows. The services (including sub-services) that depend on flows in the cryosphere would have contributions more relevant to the targets in SDG 5, 6, and 7 , while those depending on stocks would have contributions leaning more towards the targets in SDG 3, 4, 8, 9, 12, and 13. Both affect SDG 1, 2, 10, 11, 14, and 15. All SDGs logos sourced from www.un.org/sustainabledevelopment/development-agenda (accessed on 17 November 2021).

For SEP 1, which addresses sustainable basic needs, it mainly depends on the freshwater (flows), runoff regulation (flow), climate regulation (stocks), research and education (flow and stocks), and infrastructure and engineering (stocks). The widespread cryosphere resources provide the fundamentals for human beings in mountain areas, including fresh water, living environment, living conditions, etc. $[17,33]$. The pathway to SEP 1 needs to consider the tradeoff effect between freshwater and runoff regulation and those pertinent to climate regulation, infrastructure, and engineering. The coordination among governance and economic finance levers is essential to enable the pathway to strengthen human well-being and capabilities.

For SEP 2, which addresses the sustainable economy, it mainly depends on the freshwater (flows), runoff regulation (flows), research and education (flows and stocks), and infrastructure and engineering (stocks). The cryosphere promotes economic development and reduces externality costs to a certain extent [60]. In addition, cryosphere tourism based on stocks is the direction to achieve a low-carbon economy $[36,40]$. The pathway to meet the transformation for SEP 2 needs to consider the tradeoffs effect between the services related cryospheric flows and religion, spirit, culture (stocks), and aesthetic and recreation (stocks) pertinent to cryosphere tourism. The lever of science and technology is essential to the balance of cryospheric resource consumption and economic development.

For SEP 3, which addresses sustainable agriculture, it mainly depends on the freshwater (flows) and runoff regulation (flows) associated with the cryospheric flows. As the 
most vulnerable economic sector to climate change, agriculture irrigation heavily relies on the meltwater supply in arid and semi-arid regions [57-59]. The allocation of meltwater at local and regional scales is a major topic for decision-makers [58]. The pathway to SEP 3 needs to consider the synergies effect between the primary services related to those pertinent to climate regulation (flows and stocks), hydrothermal regulation (flows), and 'habitation' (flows and stocks). The lever of governance to manage the cryospheric flows is essential to enable the pathway to build food systems and healthy nutrition patterns under climate change.

For SEP 4, which addresses sustainable energy, it mainly depends on the clean energy (flows), which are in synergy with the freshwater (flows) and research and education (flows). Hydropower generation is efficient for the realization of energy supply and substitution, which is significant to the $1.5^{\circ} \mathrm{C}$ warming of the Paris climate agreement [35]. Extensive collaboration among those services are priorities to realize the pathway to the SEP 4 . The levers of financing economic development and science and technology are essential to reservoir construction for energy decarbonization and universal access to energy under climate change.

For SEP 5, which addresses sustainable societies, it mainly depends on the infrastructure and engineering (stocks), research and education (flows and stocks), freshwater (flows), and climate regulation (flows and stocks). The cryosphere services enhance the abilities to resist risks [41] and alleviate social inequality caused by climate change [23]. The pathway to SEP 5 needs to consider the tradeoff effect between the services related to cryospheric stocks and those pertinent to freshwater (flows) and runoff regulation (flows). The levers of governance and individual and collective actions are essential to promoting urban and peri-urban development.

For SEP 6, which addresses sustainable ecology, it mainly depends on the freshwater (flows), runoff regulation (flow), climate regulation (flow and stocks), habitation (flow and stocks), and hydrothermal regulation (flow and stocks). The cryosphere maintains the ecosystem's stability and climate change within the planetary boundaries [61] on a large scale. Although the synergies effect services related to the cryospheric flows are significant, the pathway to SEP 6 needs to consider the tradeoff effect among these services. The levers of individual and collective action and science technology are essential to strengthen the awareness of environmental protection and international cooperation to secure global environmental commons.

\section{Conclusions}

The cryosphere provides services from which societies may benefit. The study establishes the cryosphere services in high mountains in terms of provisioning, regulating, cultural, and supporting to link the 15 SDGs and 62 targets, reflecting human essential needs, ecological conservation, and economic development. As demonstrated in the firstpass assessment by establishing direct and indirect relations between services and SDGs, the contribution of different services to SDGs can be complex. Overall, the goals mostly relevant to the cryosphere services are 'no poverty' (SDG 1), 'zero hunger' (SDG 2), 'clean water and sanitation' (SDG 6), 'sustainable cities and communities' (SDG 11), 'responsible consumption and production' (SDG 12), and 'life on land' (SDG 15).

A services-SDG targets network was developed for the assessment of centrality and modularity to delineate the inherent complexities of the cryosphere services in achieving the SDGs. 'Research and education', 'climate regulation', 'runoff regulation', and 'freshwater' are ones that show the highest centrality among the services in contributing to the interconnected SDG targets. Meanwhile, those that benefited the most from the services are the SDG targets with the highest eigenvector centrality in the network, including 'sustain economic growth with national circumstances' (target 8.1), 'protect the cultural and natural heritage' (target 11.4), 'sustainable of terrestrial and inland freshwater ecosystems' (target 15.1), 'ensure the conservation of mountain ecosystems' (target 15.4), 'reduce the degrada- 
tion of natural habitats' (target 15.5), 'protect and restore water-related ecosystems' (target 6.6), and 'sustainable management and efficient use of natural resources' (target 12.2).

It was also pointed out that the use of cryosphere services for SDG targets can be directed to the SEPs for effective implementation pathways, with their emphasis on the targets in association with basic human needs, economy, agriculture, energy, society, and environment in a more systematic and integrated approach. As a result, the specific cryosphere services in alignment with the SEPs were identified in supporting SDGs in high mountains. It was found that the 'research and education' is able to provide fundamental support to all SEPs, while 'freshwater' together with 'runoff regulation' and 'climate regulation' affect most of the SEPs considerably. In addition to shifting towards sustainable economies (SEP 2) and strengthening human well-being (SEP 1), the 'religion, spirit, culture' and 'aesthetic and recreation' also effectuate the advance of global environmental commons (SEP 6). Overall, the pathways to meet the 2030 SDG agenda in high mountains have to consider the tradeoffs and synergies between the cryosphere services, and have to be established through combined efforts in governance, financing, individual and collective actions, and science and technology.

Supplementary Materials: The following supporting information can be downloaded at: https: / / www.mdpi.com/article/10.3390/su14020791/s1, Table S1: the interlinkage of cryosphere services with SDG targets; Table S2: the eigenvector centrality of SDG targets in five communities of the developed network; Table S3: The classification of the targets related to CS with the six entry points; Table S4: the eigenvector centralities of targets in six entry point networks; Table S5: direct and indirect casual effects of the cryosphere services on SDG targets, developed on the basis of references.

Author Contributions: Funding acquisition, W.Z.; writing-original draft, J.Z.; writing-review and editing, J.Z., W.Z., S.L. and W.K. All authors have read and agreed to the published version of the manuscript.

Funding: This research was funded by the Strategic Priority Research Program of Chinese Academy of Sciences, grant number XDA20100305; National Science Foundation of China, grant number 41971083; And the Second Tibetan Plateau Scientific Expedition and Research Program (STEP), grant number 2019QZKK0208.

Institutional Review Board Statement: Not applicable.

Informed Consent Statement: Not applicable.

Data Availability Statement: The data presented in this study are available at the Supplementary Materials.

Acknowledgments: The completion of this article benefited from the efforts of all authors. Support was obtained from other researchers who provided valuable insights into the link between cryosphere services and SDGs; we express our sincere gratitude to them.

Conflicts of Interest: The authors declare that they have no conflict of interest.

\section{References}

1. IPCC. Climate Change 2007: Impacts, Adaptation, and Vulnerability, Contribution of Working Group II to the Fourth Assessment Report of the Intergovernmental Panel on Climate Change (IPCC); Cambridge University Press: Cambridge, UK, 2007.

2. IPCC. Climate Change 2014: Impacts, Adaptation, and Vulnerability. Part A: Global and Sectoral Aspects, Contribution of Working Group II to the Fifth Assessment Report of the Intergovernmental Panel on Climate Change (IPCC); Cambridge University Press: Cambridge, UK, 2014.

3. Marzeion, B.; Kaser, G.; Maussion, F.; Champollion, N. Limited influence of climate change mitigation on short-term glacier mass loss. Nat. Clim. Change 2018, 8, 305-308. [CrossRef]

4. Dehecq, A.; Gourmelen, N.; Gardner, A.S.; Brun, F.; Goldberg, D.; Nienow, P.W.; Berthier, E.; Vincent, C.; Wagnon, P.; Trouve, E. Twenty-first century glacier slowdown driven by mass loss in High Mountain Asia. Nat. Geosci. 2019, 12, 22-29. [CrossRef]

5. Li, C.; Su, F.; Yang, D.; Kai, T.; Kan, B. Spatiotemporal variation of snow cover over the Tibetan plateau based on MODIS snow product, 2001-2014. Int. J. Climatol. 2018, 38, 708-728. [CrossRef]

6. Biskaborn, B.K.; Smith, S.L.; Noetzli, J.; Matthes, H.; Vieira, G.; Streletskiy, D.A.; Schoeneich, P.; Romanovsky, V.E.; Lewkowicz, A.G.; Abramov, A.; et al. Permafrost is warming at a global scale. Nat. Commun. 2019, 10, 264. [CrossRef] 
7. Zou, D.; Lin, Z.; Yu, S.; Chen, J.; Cheng, G. A new map of permafrost distribution on the Tibetan Plateau. Cryosphere 2017, 11, 2527-2542. [CrossRef]

8. Gruber, S.; Fleiner, R.; Guegan, E.; Panda, P.; Schmid, M.O.; Stumm, D.; Wester, P.; Zhang, Y.; Zhao, L.; Gruber, S. Review article: Inferring permafrost and permafrost thaw in the mountains of the Hindu Kush Himalaya region. Cryosphere 2017, 11, 81-99. [CrossRef]

9. Immerzeel, W.W.; Lutz, A.F.; Andrade, M.; Bahl, A.; Biemans, H.; Bolch, T.; Hyde, S.; Brumby, S.; Davies, B.J.; Elmore, A.C.; et al. Importance and vulnerability of the world's water towers. Nature 2020, 577, 364-369. [CrossRef]

10. Pritchard, H.D. Asia's shrinking glaciers protect large populations from drought stress. Nature 2019, 569, 649-654. [CrossRef]

11. Diaz, S.; Pascual, U.; Stenseke, M.; López, B.M.; Watson, R.T.; Molnár, Z.; Hill, R.; Chan, K.M.A.; Baste, I.A.; Brauman, K.A.; et al. Assessing nature's contributions to people. Science 2018, 359, 270-272. [CrossRef]

12. IPCC. Special Report on the Ocean and Cryosphere in a Changing Climate (SROCC); IPCC Intergovernmental Panel on Climate Change: Geneva, Switzerland, 2019.

13. Viviroli, D.; Kummu, M.; Meybeck, M.; Kallio, M.; Wada, Y. Increasing dependence of lowland populations on mountain water resources. Nat. Sustain. 2020, 3, 917-928. [CrossRef]

14. Daily, G. Nature's Services: Societal Dependence on Natural Ecosystems; Island Press: Washington, DC, USA, 1997.

15. Costanza, R.; D’Arge, R.; Groot, R.D.; Farber, S.; Grasso, M.; Hannon, B.; Limburg, K.; Naeem, S.; O’Neill, R.V.; Paruelo, J.; et al. The value of the world's ecosystem services and natural capital. Nature 1997, 387, 253-260. [CrossRef]

16. Xiao, C.; Wang, S.; Qin, D. A preliminary study on cryosphere service function and its value estimation. Progress. Inquisitiones Mutat. Clim. 2016, 12, 45-52. [CrossRef]

17. Wang, X.; Liu, S.; Zhang, J. A new look at roles of the cryosphere in sustainable development. Adv. Clim. Change Res. 2019, 10, 124-131. [CrossRef]

18. Yao, T.; Chen, Y.; Yan, L.I.; Qian, Q.; Guo, G. TPE international program: A program for coping with major future environmental challenges of the third pole region. Prog. Georg. 2014, 33, 884-892.

19. United Nations. Transforming Our World: The 2030 Agenda for Sustainable Development; Working Papers; United Nations: New York, NY, USA, 2015

20. United Nations. Sustainable Development Goals Report 2020; United Nations: New York, NY, USA, 2020.

21. Fu, B.; Wang, S.; Zhang, J.; Hou, Z.; Li, J. Unravelling the complexity in achieving the 17 sustainable-development goals. Natl. Sci. Rev. 2019, 6, 386-388. [CrossRef]

22. Soergel, B.; Kriegler, E.; Weindl, I.; Rauner, S.; Dirnaichner, A.; Ruhe, C.; Hofmann, M.; Bauer, N.; Bertram, C.; Bodirsky, B.L.; et al. A sustainable development pathway for climate action within the UN 2030 Agenda. Nat. Clim. Change 2021, 11, 656-664. [CrossRef]

23. Wester, P.; Mishra, A.; Mukherji, A.; Shrestha, A.B. (Eds.) International Centre for Integrated Mountain Development (ICIMOD) In The Hindu Kush Himalaya Assessment: Mountains, Climate Change, Sustainability and People; Springer Nature Switzerland AG: Cham, Switzerland, 2019.

24. Nilsson, M.; Griggs, D.; Visbeck, M. Map the interactions between sustainable development goals. Nature 2016, 534, 320-322 [CrossRef]

25. Griggs, D.; Nilsson, M.; Stevance, A.S.; McCollum, D. A Guide to SDG Interactions: From Science to Implementation; International Council for Science (ICSU): Paris, France, 2017.

26. Liu, J.; Hull, V.; Godfray, H.C.J.; Tilman, D.; Gleick, P.; Hoff, H.; Wostl, C.P.; Xu, Z.; Chung, M.; Sun, J.; et al. Nexus approaches to global sustainable development. Nat. Sustain. 2018, 1, 466-476. [CrossRef]

27. Barbier, E.B.; Burgess, J.C. Sustainable development goal indicators: Analyzing trade-offs and complementarities. World Dev. 2019, 122, 295-305. [CrossRef]

28. Dawes, J. SDG interlinkage networks: Analysis, robustness, sensitivities, and hierarchies. World Dev. 2022, 149, 105693. [CrossRef]

29. Zhou, X.; Moinuddin, M. (Eds.) Sustainable Development Goals Interlinkages and Network Analysis: A Practical Tool for SDG Integration and Policy Coherence. In Institute for Global Environmental Strategies (IGES) Research Report; Institute for Global Environmental Strategies: Hayama, Japan, 2017.

30. United Nations. Global Sustainable Development Report 2019: The Future is Now-Science for Achieving Sustainable Development; United Nations: New York, NY, USA, 2019.

31. Millennium Ecosystem Assessment (MA). Ecosystems and Human Well-Being: Synthesis; Island Press: Washington, DC, USA, 2005.

32. Xiao, C.; Su, B.; Wang, X.; Qin, D. Cascading risks with cryospheric functions and their services declining. Chin. Sci. Bull. 2019, 12, 45-52. [CrossRef]

33. Su, B.; Xiao, C.; Chen, D.; Qin, D.; Ding, Y. Cryosphere services and human well-being. Sustainability 2019, 11, 4365. [CrossRef]

34. Diffenbaugh, N.S.; Burke, M. Global warming has increased global economic inequality. Proc. Natl. Acad. Sci. USA 2019, 116, 9808-9813. [CrossRef]

35. Farinotti, D.; Round, V.; Huss, M.; Compagno, L.; Zekollari, H. Large hydropower and water-storage potential in future glacier-free basins. Nature 2019, 575, 341-344. [CrossRef]

36. Wang, S.; Xu, X.; Deng, J.; Zhou, L. Chinese skiing-tourism destination: Spatial patterns, existing problems and development countermeasures. J. Glaciol. Geocryol. 2017, 39, 902-909. 
37. Jeelani, G.; Feddema, J.J.; Veen, C.J.V.D.; Stearns, L. Role of snow and glacier melt in controlling river hydrology in Liddar watershed (western Himalaya) under current and future climate. Water Resour. Res. 2012, 48, 12508. [CrossRef]

38. Milner, A.M.; Khamis, K.; Battin, T.J.; Brittain, J.E.; Brown, L.E. Glacier shrinkage driving global changes in downstream systems Proc. Natl. Acad. Sci. USA 2017, 114, 9770-9778. [CrossRef]

39. Melnikov, V.; Gennadinik, V.; Kulmala, M.; Lappalainen, H.K.; Zilitinkevich, S. Cryosphere: A kingdom of anomalies and diversity. Atmos. Chem. Phys. 2018, 18, 6535-6542. [CrossRef]

40. Nuesser, M. Socio-hydrology: A new perspective on mountain waterscapes at the nexus of natural and social processes. Mt. Res. Dev. 2017, 37, 518-520. [CrossRef]

41. Cheng, G.D. Permafrost studies in the Qinghai-Tibet plateau for road construction. J. Cold Reg. Eng. 2005, 19, 19-29. [CrossRef]

42. Bateman, I.J.; Mace, G.M. The natural capital framework for sustainably efficient and equitable decision making. Nat. Sustain. 2020, 3, 776-783. [CrossRef]

43. Mastrandrea, M.; Field, C. Guidance note for lead authors of the Ipcc fifth assessment report on consistent treatment of uncertainties. Intergovernmental panel on climate change (IPCC). Heart Dev. 2010, 28, 307-329. [CrossRef]

44. Blicharska, M.; Smithers, R.J.; Mikusiński, G.; Rnnbck, P.; Sutherland, W.J. Biodiversity's contributions to sustainable development. Nat. Sustain. 2019, 2, 1083-1093. [CrossRef]

45. Newman, M. The structure of scientific collaboration networks. Proc. Natl. Acad. Sci. USA 2001, 98, 404-409. [CrossRef]

46. Newman, M. Scientific collaboration networks. I. Network construction and fundamental results. Phys. Rev. E 2001, 64, 016131. [CrossRef]

47. Mathieu, J.; Tommaso, V.; Sebastien, H.; Mathieu, B.; Muldoon, M.R. ForceAtlas2, a continuous graph layout algorithm for handy network visualization designed for the Gephi software. PLoS ONE 2014, 9, e98679. [CrossRef]

48. Bonacich, P. Factoring and weighting approaches to status scores and clique identification. J. Math. Sociol. 1972, 2, 113-120. [CrossRef]

49. Newman, M. Modularity and community structure in networks. Proc. Natl. Acad. Sci. USA 2006, 103, 8577-8582. [CrossRef]

50. Radicchi, F.; Fortunato, S.; Castellano, C. Universality of citation distributions: Towards an objective measure of scientific impact. Proc. Natl. Acad. Sci. USA 2008, 105, 17268-17272. [CrossRef]

51. David, M. Hierarchical modularity in human brain functional networks. Front. Neuroinform. 2010, 3, 37. [CrossRef]

52. Blondel, V.D.; Guillaume, J.L.; Lambiotte, R.; Lefebvre, E. Fast unfolding of communities in large networks. J. Stat. Mech.-Theory Exp. 2008, 10, P10008. [CrossRef]

53. Biemans, H.; Siderius, C.; Lutz, A.F.; Nepal, S.; Ahmad, B.; Hassan, T.; von Bloh, W.; Wijngaard, R.R.; Wester, P.; Shrestha, A.B.; et al. Importance of snow and glacier meltwater for agriculture on the Indo-Gangetic plain. Nat. Sustain. 2019, 2, 594-601. [CrossRef]

54. Hugonnet, R.; McNabb, R.; Berthier, E.; Menounos, B.; Nuth, C.; Girod, L.; Farinotti, D.; Huss, M.; Dussaillant, I.; Brun, F.; et al Accelerated global glacier mass loss in the early twenty-first century. Nature 2021, 592, 726-731. [CrossRef]

55. Zemp, M.; Frey, H.; Gartner-Roer, I.; Nussbaumer, S.U.; Hoelzle, M.; Paul, F.; Haeberli, W.; Denzinger, F.; Ahlstram, A.P.; Anderson, B.; et al. Historically unprecedented global glacier decline in the early 21st century. J. Glaciol. 2015, 61, 745-762. [CrossRef]

56. Bokhorst, S.; Pedersen, S.H.; Brucker, L.; Anisimov, O.; Callaghan, T.V. Changing Arctic snow cover: A review of recent developments and assessment of future needs for observations, modelling, and impacts. AMBIO 2016, 45, 516-537. [CrossRef]

57. Li, Z.; Feng, Q.; Wang, Q.J.; Yong, S.; Li, J.; Li, Y.; Wang, Y. Quantitative evaluation on the influence from cryosphere meltwater on runoff in an inland river basin of China. Glob. Planet. Change 2016, 143, 189-195. [CrossRef]

58. Chen, Y.; Li, Z.; Fang, G.; Li, W. Large hydrological processes changes in the transboundary rivers of central Asia. J. Geophys. Res.-Atmos. 2018, 123, 5059-5069. [CrossRef]

59. Rodell, M.; Famiglietti, J.S.; Wiese, D.N.; Reager, J.T.; Beaudoing, H.K.; Landerer, F.W.; Lo, M.H. Emerging trends in global freshwater availability. Nature 2018, 557, 651-659. [CrossRef]

60. Tietenberg, T.; Lewis, L. Environmental and Natural Resource Economics; Routledge Press: New York, NY, USA, 2018.

61. Steffen, W.; Richardson, K.; Rockstrom, J.; Cornell, S.E.; Fetzer, I.; Bennett, E.M.; Biggs, R.; Carpenter, S.R.; Vries, W.D.; Wit, C.; et al. Planetary boundaries: Guiding human development on a changing planet. Science 2015, 347, 1259855. [CrossRef] 